\section{Selected aspects of occupational health and safety practices in small scale factories in the area of Medical Officer Health, Kotte}

\section{D.B.D.L. Samaranayake ${ }^{1}$, M.W. Gunathunga ${ }^{2}$}

\section{Abstract \\ Objectives}

The objective of this study was to describe the health hazards, welfare facilities and health and safety related practices in small-scale factories in a selected $\mathrm{MOH}$ area.

\section{Methodology}

A descriptive cross sectional study was conducted among small scale factories in the $\mathrm{MOH}$ area Kotte. The entire population of 82 factories with less than 50 workers was studied. The occupiers were interviewed using an intervicwer administered questionnaire to identify the health related practices, and an observation schedule was used to assess the health hazards and welfare facilities.

\section{Results}

Availability of sanitary conveniences (94\%), drinking water $(84 \%)$ and washing facilities (99\%) was satisfactory. The availability and adequacy of dining rooms, rest rooms and first aid facilities were extremely poor. The workers were exposed to multiple health hazards in the workplaces. The commonest hazards identified were poor house keeping (90\%), clectrical hazards (88\%), excessive noise $(80 \%)$, unguarded machinery (73\%), ergonomic hazards (70\%) and poor cleanliness $(57 \%)$

Only $25 \%$ of factories trained the workers on safe use of machinery. Welders' eye guards were provided in all the factories that carried out welding but no other personal protective devices were provided to the workers were exposed to multiple hazards like dust, chemicals and fumes. Provision of health services was limited to taking the patient to the hospital in an emergency. Only $10 \%$ of the factory managers were aware of the accident notification system and almost all the factories did not comply with it.

\section{Conclusions}

The occupational health status of small scale factory workers was found to be highly unsatisfactory with exposure to multiple hazards and poor welfare facilities. The coordinated action of labour authorities, the primary health care team

1. Lecturer, Department of Community Medicine, Faculty of Medicine, University of Colombo

2. Senior Lecturer, Department of Community Medicine, Faculty of Medicine, University of Colombo

Journal of the Community physicians of Sri Lanka and the factory management is recommended to improve this situation.

\section{Key words}

small scale industries, occupational hazards. welfare facilities

\section{Introduction}

Small and medium-sized enterprises are a critical factor in economic development and creation of jobs throughout the world (1). They employ a significant part of the global labour force. These employees belong to the under-served working population who do not fully benefit from available knowledge and experience related to health and safety at work (2).

The number of small scale industries in Sri Lanka has increased with the growth of the population and rapid urbanization. In 2004, there were 121,426 establishments with less than 10 workers with a total labour force of nearly 300,000 (3).

Available findings on occupational health status in small-scale industries (SSIs) in Sri Lanka reveal unsatisfactory health and safety conditions with exposure to multiple hazards (4). SSIs are subject to numerous workplace hazards like dust, heat stress, toxic substances, noise, vibration and poor hygiene (5). The Factories Ordinance No.45 of 1942 provides the legal framework for occupational health of factory workers in Sri Lanka. The small scale factories are covered by this legislation which specifies provisions for the health, safety and welfare of factory workers.

The working condition of these establishments is a strong determinant of the productivity as well as the health of their work force. Therefore, improving the occupational health status of these under-served workplaces has become a priority. The objective of this study was to describe the health hazards, welfare facilities and health and safcty relatcd practiccs in small-scale factories in the Kotte $\mathrm{MOH}$ area with a view of making suggestions for improvement.

\section{Methodology}

The study design was a descriptive cross sectional study which was conducted in two steps.

- Preliminary survey to identify the smallscale factories in the area.

- Descriptive cross sectional study of the workplaces to identify health hazards, health related facilities and practices in small scale factories.

The study was conducted in the Medical Officer of Health area Kotte. All the small scale factories (employing 50 or less workers) were identified using the information available with the Public

Volume 11, No.2, December 2006 
Health Inspectors and the Public Health Midwives. Completeness was achieved by a house to house survey. Two study instruments, an observation schedule and an interviewer administered questionnaire, were utilized. The interviewer administered questionnaire was targeted for the occupiers/managers of the factories. It was intended to identify health and safety related practices in the factories. The questionnaire was prepared in English and translated to Sinhala. The questionnaire consisted of four parts- basic information about the factory and the workers, safety related practices, first-aid and health facilities and accidents and related practices. The observation schedule was designed to assess the health hazards and welfare facilitics. It covered the following areas- physical environment, electrical safety, cleanliness and housekeeping, machinery and moving parts, ergonomic hazards, chemicals, fumes and gases and welfare facilities. It was completed by the chief investigator by observing the work area and welfare facilities of each factory. In the situations where there were more than one work room the average condition of all rooms was considered. When setting the standards for observing the work environment. the requirements specified in the Factories Ordinance were used (6). Noise levels were measured objectively using a standard CR: 303 noise level meter. The study instruments were pre-tested and necessary changes were made. Ethical clearance for the study was obtained from the Ethical Review Committee, Faculty of Medicine, University of Colombo.

\section{Results}

There were 82 small scale factories in Kotte and all of them were included in the study. Out of those, 26 were not registered at the local government authorities. Sixty four out of 82 factories $(78 \%)$ had $1-10$ workers. 15 (18.3\%) had $11-20$ workers and $3(3.7 \%)$ had more than 20 workers. The 82 factories were involved in a diverse range of activities. Table 1 gives the different types of activities carried out in these

Table 1 - Distribution of 82 small scale factories in Kotte according to type of industry

\begin{tabular}{lcc}
\hline Type of Industry & $\begin{array}{c}\text { No. of } \\
\text { Factories }\end{array}$ & $(\%)$ \\
\hline Garments & 22 & $(26.8)$ \\
Printing & 16 & $(19.5)$ \\
Bakeries & 06 & $(7.3)$ \\
Food production & 06 & $(7.3)$ \\
Vehicle repair & 05 & $(6.1)$ \\
Welding & 04 & $(4.9)$ \\
Plastic items & 04 & $(4.9)$ \\
Steel works & 04 & $(4.9)$ \\
Others & 15 & $(18.3)$ \\
\multicolumn{1}{c}{ Total } & $\mathbf{8 2}$ & $(\mathbf{1 0 0})$ \\
\hline
\end{tabular}

Journal of the Community physicians of Sri Lanka establishments. Garment industry was the commonest, which was 22 (26.8\%) out of the 82 factories.

Out of the total work force of 645 employed in the factories, $389(61.1 \%)$ were males. Table 2 gives the distribution of the employment status of the total workforce. When considering the manpower levels the work force was employed at, it was shown that a majority of $433(67 \%)$ of the work

Table 2 - Distribution of workers in small scale factories according to their employment status

\begin{tabular}{lcc}
\hline $\begin{array}{c}\text { Employment } \\
\text { Status }\end{array}$ & $\begin{array}{c}\text { No. of } \\
\text { workers }\end{array}$ & $\mathbf{( \% )}$ \\
\hline Permanent & 291 & $(45.1)$ \\
Temporary & 283 & $(43.9)$ \\
Casual & 17 & $(2.6)$ \\
Contract basis & 54 & $(8.4)$ \\
\multicolumn{1}{c}{ Total } & $\mathbf{6 4 5}$ & $(\mathbf{1 0 0})$ \\
\hline
\end{tabular}

force were employed as machine operators and that 161 (25\%) were employed as labourers.

Table 3 shows the availability and adequacy of welfare facilities. Sanitary conveniences (94\%), drinking water (84\%) and washing facilities (99\%) were available in most factories. On the other hand, availability and adequacy of dining rooms, rest rooms and first aid facilities were extremely poor. Provision of first aid facilities was grossly insufficient; only five factories had

Table 3 - A vailability and adequacy of welfare facilities in 82 small scale factories in Kotte

\begin{tabular}{lcc}
\hline Welfare Facility & $\begin{array}{c}\text { Facility } \\
\text { Available } \\
(\%)\end{array}$ & $\begin{array}{c}\text { Facility } \\
\text { Adequate } \\
(\%)\end{array}$ \\
\hline & & \\
Sanitary & & \\
conveniences & $77(93.9)$ & $75(97.4)$ \\
Drinking water & $69(84.1)$ & $59(85.5)$ \\
Washing facilities & $81(98.8)$ & $68(83.9)$ \\
Dining area & $17(20.7)$ & $03(17.6)$ \\
Resting area & $05(06.1)$ & $00(00.0)$ \\
First-aid box & $05(06.1)$ & $00(00.0)$ \\
\hline
\end{tabular}

*As a percentage of the no. of factories where the

first aid boxes all of which were far below the requirements of Factories Ordinance.

Out of the 82 factories, $48(58.6 \%)$ were situated in separate buildings, 27 (33\%) were situated in a separate room in the owner's house whereas in 7 (8.5\%) the industrial activity was carried out in the living area of the owner's house. The commonest hazards identified were excessive 
noise, electrical hazards, poor housc keeping, poor cleanliness, unguarded machinery and ergonomic hazards. There were 62 factories involved in noise-generating activities. Only 16 (19.5\%) out of the 62 factories had noise levels below $85 \mathrm{dBA}$ at the time of data collection. Sixty six lactories were using electricity in the production process. Table 4 summarizes the electrical hazards identified in those. In 58 factories $(87.9 \%)$ there were conductors below head level and unsafe connections were seen in $56(84.8 \%)$ factories. Guarding of machinery was assessed according to the standards specified in the Factories Ordinance. According to that out of 64 factories using machinery, $11(17.2 \%)$ had unguarded moving parts in prime movers and 16 (25\%) had unguarded transmitting machinery. Forty seven factories $(73.4 \%)$ had unguarded dangerous parts

Table 4 - Electrical hazards in 66 sinall scale factories in Kotte

\begin{tabular}{ll}
\hline \multicolumn{1}{c}{ Hazard } & $\begin{array}{c}\text { No. of } \\
\text { Factories } \\
(\% *)\end{array}$ \\
\hline & \\
Exposed conductors & $36(54.5)$ \\
Conductors below head level & $58(87.9)$ \\
No functioning trip switch & $19(28.8)$ \\
Unsafe connections & $56(84.8)$ \\
\hline
\end{tabular}

* As a percentage of the total no. of factories using electricity ( $n=66$ )

which mainly consisted of blades of cutting equipment.

The prevalence of general, physical, housekeeping and ergonomic hazards in the 82 fictories is summarized in Table 5. Poor ventilation was noticed in $29(35 \%)$ factories. Tripping hazards were seen in $74(90 \%)$ and workers wcre exposed to repetitive movements in 58 (70\%) factories. Table 6 summarizes the findings on chemical hazards. In $20(66.6 \%)$ out of 30 factories using
Table 5 - Hazards in the work environment of 82 small scale factories in Kotte

\begin{tabular}{lc}
\hline \multicolumn{1}{c}{ Hazard } & $\begin{array}{c}\text { No. of } \\
\text { Factorics } \\
(\% *)\end{array}$ \\
\hline General Environment & $20(24.4)$ \\
Inadequate space & $29(35.4)$ \\
Poor ventilation & $04(4.9)$ \\
Poor general lighting & $06(7.3)$ \\
Excessive heat & $16(19.5)$ \\
Dust & $1518.3)$ \\
Water not draining from work & \\
area & \\
Housekeeping & $74(90.2)$ \\
Tripping hazards & $38(46.3)$ \\
Sharp instruments lying about & $04(4.9)$ \\
Risk of objects falling on to & \\
workers & $08(9.8)$ \\
Slipping hazards & \\
Ergonomic Hazards & $14(17.1)$ \\
Handling heavy loads in & \\
incorrect postures & \\
Working with hands above & $09(11.0)$ \\
shoulder level & \\
Repetitive movements & $58(70.1)$ \\
Working in squatting position & $26(31.7)$ \\
Working in bending position & $55(67.1)$ \\
\hline A & \\
\hline
\end{tabular}

* A s a \% of the total no. of factories $(n=82)$

chemicals, the workers handling the chemicals were not aware what the chemicals used were. Chemicals were stored in the work area itself in $27(90.0 \%)$ of the factories. Labelling of the chemical containers was poor and in $64 \%$ of the factories the workers were unablc to read the available labels. Chemical safety cards were not available in any of the 30 factorics and none of the managers or occupiers was aware of those.

The managers / occupiers were questioned on the safety related activities carried out in their work places. It was noticed that safety was not

Table 6 - Chemical hazards in 30 small scale factories using chemicals in Kotte

Factors leading to Chemical Hazards
No. of Factorics $(\% *)$

Workers not aware of chemicals used

Chemicals stored in the work area

Some of the chemical containers not labeled

22(73.3)

All the chemical containers not labeled

Workers unable to read some of the labels

$05(16.6)$

Workers unable to read any of the labels

$16(64.0)^{* *}$

Chemical safety cards not available

$09(36.0)^{* * *}$

$30(100.0)$

* As a percentage of factories using chemicals $(n=30)$
$* *$ As a percentage of factorics with at least some chemical containers labeled. $(n=25)$ 
recognized as a need in any of the factories. There were 67 factories which used machinery which had the potential to cause injurics to the workers. Out of those only 17 (25.4\%) factories provided some form of training to the workers on the safe use of the machines. In the remaining $50(74.6 \%)$ factorics the new workers started using the machinery without any training to learn by trial and error.

Provision and use of personal protective devices (PPDs) was assessed by questioning the management regarding the provision of PPDs and observing their use by the workers. Although dust and fumes were a problem in 18 factories none of them had provided masks. None of the 30 factories where the workers handled chemicals had provided them with gloves. Six out of the 13 factories with welding activities provided the workers with eye guards.

During the pre-test, it was noticed that the concept of occupational health services was totally unknown in this setting. Thercfore the factory management was questioned on the curative care that was provided to the workers in an emergency during working hours. None of the factorics had the ability to provide the scrvices of a doctor, neither full time nor part time. The commonest practice was to take the patient to the nearest general practitioner $(73.2 \%)$ or the government hospital $(25.6 \%)$. Facilities to transport a patient were available in $22(27 \%)$ of the fuctorics.

Only 8 (9.8\%) occupiers were aware of the accidents notifiable according to the Factories Ordinance. Therefore information about notifiable accidents had to be obtained after educating them about notification. There were 11 factories where notifiable accidents had occurred in the past year. The number of notifiable accidents was 11 and accordingly the rate of notifiable accidents per 1000 workcrs was 17. Only onc fuctory had notified the accident and recorded it in the general register. In all other $8 \mathrm{I}$ factories a general register was not available. There were 35 factories where minor accidents had occurred during the past year. The number of minor accidents was 65 and the rate of minor accidents per 1000 workers was 100.8. Therefore, the total accident rate was 117.8 per 1000 workers.

\section{Discussion}

Occupational health is identified as a component of primary health care in Sri Lanka but there is no organized system to provide the scrvices related to occupational health. The legislative framework regarding occupational health in Sri Lanka is limited mainly to the Factories Ordinance. Therefore, recommendations in the Factorics
Ordinance were used as the standard against which the health, safety and welfarc provisions in the factories were assessed.

The study instruments included an observation schedule and an interviewer administered questionnaire. Considering the immense diversity of the activities carried out at the small scale factories, the study instruments were directed to identify the general occupational health hazards common to all small scale factories rather than those specific to individual industries. In the obscrvation schedule, the noise levels were measured objectively and the ventilation and space were assessed objectively according to the criteria specified in the Factories Ordinance (6). The presence of electrical, ergonomic, chemical and housekeeping hazards was assessed against a set of predetermined criteria formulated according to the opinion of a panel of experts.

The welfare facilities available in these small scale factories are seen to be far from the optimum and this situation seems to be a common finding in the small scale industries and the informal sector in other countries also $(7,8)$. These unsatisfactory welfare facilities show that the workers of small scale factories are working in environments that do not effectively fulfill their basic amenities. These unsatisfactory working conditions could lead to adverse health conditions. both physical and psychological.

In $8.5 \%$ factories there was no clear demarcation between the work area and the living area. Industries like garments, making shoes and preparing food were housed in the living arcas of the owners' houses exposing the family members including children to health hazards like dust. sharp instruments, unsafe clectrical connections and smoke.

Excessive noise is found (o) be a common problem with $80 \%$ factories having more than the standard limit of $85 \mathrm{dBA}$. The high noise level was not continuous in most of these factorics, therefore not all the factories with above $85 \mathrm{~dB} \Lambda$ can be considered as having harmful noise levels. None of those factories had made any attempt to control the noise exposure of the workers. Exposure to excessive noise levels places these workers in the risk of devcloping adverse health effects like increased blood pressure, fatigue, increased heart rate and most importantly noise induced hearing loss.

Poor electrical safcty was obscrved in a majority of factories with conductors below head level $(88 \%)$, unsafe connections $(85 \%)$ and exposed conductors $(54 \%)$. It was noticed that most of the 
occupiers were not aware of the electrical hazards present. Housekeeping hazards which could be avoided without any additional cost, was neglected in most factories. Guarding of machinery was found to be unsatisfactory. Most factories used old machines without proper guards and the available guards were removed because they interfered with the work. The deticiencies observed in electrical safety, housekeeping and guarding of machinery makes these small scale factories highly unsafe work environments. This low priority given to work place safety in small scale workplaces is evident from other studics in Sri Lanka (4) as well as other countries (8-11). This situation makes the employees prone to accidents and injuries in the work settings.

This study revealed a high prevalence of ergonomic hazards mostly caused by ill designed work stations and ill fitting furniture. Ergonomic hazards were found to be prevalent in small scale industries according to findings of other studies as well (8). Exposure to ergonomically unsound work postures makes the workers prone to musculoskeletal problems and fatigue as well as leading to low productivity.

Chemical safety was found to be poor in the 30 industries using chemicals and basic precautions with regard to chemical use were not adhered to in a majority of the places. Poor chemical safety places these workers at high risk of accidental ingestion of chemicals, chemical burns and injuries. These findings agree with those conducted in other countries $(8,9)$ which describe poor chemical safety in SMEs and the informal sector.

Safcty related practices were lacking seriously with only $25 \%$ factories providing talining to the workers on safe use of machinery. Provision of personal protective devices (PPDs) wils extremely poor. Among the 82 factories which exposed the workers to a host of occupational hazards, the provision of PPDs was limited to eye guirds provided to welders. In all six factories where eye guards were provided the workers used them indicating that their enthusiasm to protect themselves was good whereas the lick of commitment was on the part of the employers.

Occupational Health Services (OHS) provided by the Factory owners / management was limited to actions taken during an illness or injury occurring during working hours in which ciase the pattient was taken to the nearest generill practilioner or government hospital. The occupational health services in the factories studied werc far below and almost non comparable with the standards specified by the ILO Convention on Occupational
Health Services 1985. The compliance with the Factories Ordinance requirement to notify major accidents and record in the general register was not practised in almost all the factories. l.ess than $10 \%$ factory managers were aware about the notification system of industrial accidents or the notifiable accidents which shows that this lack of compliance could be mainly due to poor awareness.

\section{Conclusions and Recommendations}

Small scale factory workers are exposed to multiple health hazards in their workplaces. Welfare facilities were unsatisfactory in majority of factories where even the minimum requirements of the Factories Ordinance were not provided. Occupational Health Services were found to be virtually non existent. The employers were unaware of the industrial health legislations and the requirements they are bound to fulfill under that. Overall, the small scale factories were found to have highly unsatisfactory work environments which need immediate interventions. The coordinated action of the labour authorities, primary health care team and factory management is recommended to face this challenge.

\section{Acknowledgements}

We are grateful to the WHO for providing funds and to the Medical Officer of Health and the staff of Kotte for their support.

\section{References}

1.ILO, Job Creation in Simall and Medium Enterprises Recommendation,

ILOIRI89. ILO: Geneva: 1998.

2. Mikheev MI. Occupational health and safety in Small Enterprises. Int. Arch. Occup. Env. Health. 1998; 71 : (suppl. s 10-2).

3. Department of Census and Statistics, Sri Lanka Statistical Data Sheet, 2004. Department of Census \& Statistics, Colombo.

4. Fernando GS, De Alwis WR, Jayamanne ITT, Gunaratne DR. A Sindy on Industrial Health / Work Safery measures applicable to Small and Medium Scale Industries / enterprises in Sri Lanka. 1990, Colombo: SMED Sri Lanka.

5.WHO, Health and environment in sustainable development. .WHO: Geneva:1997.

6. Factories Ordinance. Act No. 45. 1942, Govt. of Sri Lanka.

7. Ahasan MR, Khan AW, Al-Mahtab M, Faruquee SM. Small and medium-sized chemical factories in Bangladeshoccupational health and safery measures. Global Ergonomics, ed. R.B.a.J.C. PA Scott. 1998: Elsevier Science. p. 27 1-275.

8. Loewenson R. Health Impact of Occupational Risks in the Informal Sector in Zimbabwe. 1997 
[cited; Available from: http://www.ilo.org/ public/english/protection/safe work/papers/ inf zimb/index.htm\#top.

9. Nabil TW, Awan S, Goodson R. Chemical risk assessment and Occupational Hygiene preventive measures in Small and Medium sized enterprises. 1999 [cited 12.03.2005]; Available from: www.ilo.org/public/english/ protection/safework/papers/smechem.

10.Odhiambo CB. Hazards in small-scale industries in Mombasa, Kenya. African Newsletter on Occupationil Heild) and Safety., 1999; 1: 49-53.

11.Tomberg V, Forasticri V, Riwa PG, Swai,D. Occupational safety and Health in the informal sector- Intervention strategies and implementation of pilot activities in Dar es Salaam. African Newsletter on Occupational Health and Sufety. 1996: 2: 30-33. 